\title{
CHRISTMAS FACTOR (IX) DEFECT IN A CASE OF HAEMORRHAGIC THROMBOCYTHAEMIA
}

\author{
BY \\ W. E. BENNEY AND F. J. W. LEWIS \\ From the Department of Pathology, Southmead Hospital, Bristol
}

(RECEIVED FOR PUBLICATION JUNE 2, 1959)

The mechanism of bleeding in haemorrhagic thrombocythaemia is obscure. Although by definition there is always a raised platelet count, the haemorrhagic episodes cannot be satisfactorily correlated with the level of the count. In fact, thrombocythaemia can exist without bleeding manifestations (Fanger, Cella, and Litchman, 1954). The most commonly occurring laboratory defect is an abnormal bleeding time, this being increased in approximately $50 \%$ of cases (Hardisty and Wolff, 1955). The introduction of the thromboplastin generation test by Biggs and Douglas in 1953 provided a valuable method of investigation, and has been applied in many of the reported cases of haemorrhagic thrombocythaemia. Attention has, however, been focused mainly on the platelets, and the results have varied considerably. This paper presents details of a case of haemorrhagic thrombocythaemia showing a Christmas factor deficiency.

\section{Methods}

Blood Counts.-In this laboratory three were performed as described by Dacie (1950).

Clotting Mechanism.-Tests of clotting were as described by Biggs and MacFarlane (1957).

In the one-stage prothrombin test (Quick) a saline emulsion prepared from a stock of acetone-dried human brain powder, selected to give a normal clotting time of $12 \pm 1$ sec., was used.

The thromboplastin generation tests were based on the method of Biggs and Douglas (1953), the collection of blood being in accordance with Biggs and MacFarlane (1957). The only modification was that clotting was observed on slides on a specially constructed thermostatically-controlled warm stage, which enabled the moment of clotting to be gauged accurately.

Absorption by $\mathbf{A l}(\mathbf{O H})_{3 .}$-Platelet-rich normal plasma was centrifuged and the supernatant removed so as to increase the platelet concentration 10 times. The platelets were resuspended and the plasma incubated for three hours. After re-centrifuging, the supernatant was removed and treated with $\mathrm{Al}(\mathrm{OH})_{3}$.
This plasma and the same plasma before platelet concentration were compared against known Christmas disease serum in the thromboplastin generation tests. There was no significant difference in the curves produced.

\section{Case History}

Miss G.H., aged 61, presented in 1946 with a haematemesis from a peptic ulcer which later perforated. At operation the spleen was thought to be enlarged. In June, 1948, she complained of persistent headaches.

On examination, the spleen was just palpable and the blood count showed: Hb $94 \%$ (31.9 g./100 ml.); R.B.C.s $5,850,000$ per c.mm.; W.B.C.s 28,400 per c.mm. (neutrophils $64.5 \%$, juveniles $12.5 \%$, eosinophils $5.5 \%$, basophils $3.0 \%$, myelocytes $6.5 \%$, monocytes $1.0 \%$, lymphocytes $7.0 \%$ ). There was no comment on the platelets.

She was considered to be a case of chronic myeloid leukaemia and was kept under observation without treatment. The blood picture persisted for the next few years with little variation in the differential pattern.

In 1951 she was admitted to this hospital for blood transfusion following a haematemesis. A platelet count, recorded for the first time, was $1,000,000$ per c.mm. Over the following years spontaneous haemorrhagic manifestations with ecchymoses became more frequent, and by 1955 the platelet count had risen to $2,000,000$ per c.mm. and the splenomegaly had become more marked. The sternal marrow was investigated. This showed an increase of megakaryocytes and was not typical of leukaemia. -A diagnosis of haemorrhagic thrombocythaemia was substituted for that of chronic myeloid leukaemia. The Lee and White clotting time was $6 \mathrm{~min} .30 \mathrm{sec}$. the clot retraction was normal, and the bleeding time was $5 \mathrm{~min} .10 \mathrm{sec}$.

In December, 1957, she was again admitted for transfusion following haematemesis. During the next 10 months the platelet count ranged from 835,000 per c.mm. to $2,000,000$ per c.mm. The bleeding time never exceeded $5 \mathrm{~min}$. $15 \mathrm{sec}$. and the Quick onestage prothrombin index varied between $65 \%$ and $100 \%$. A prothrombin consumption test carried out in October, 1958, before treatment, gave a normal 
value of $13 \%$ and a thrombin generation test at the same time showed no abnormality.

In view of the Leeds experience (Fountain, 1958), treatment with radioactive phosphorus was suggested, and on October 31,1958 , the patient received $5 \mathrm{mc}$. $32 \mathrm{P}$ orally. By November 25 the white count had fallen to 5,600 per c.mm. and the platelet count to 500,000 per c.mm. By January, 1959, it had reached 260,000 per c.mm.

Thromboplastin Generation Studies.-The first test (Fig. 1) was performed in November, 1956. Using a normal platelet suspension, no abnormality was observed; but when the patient's platelets were used there appeared to be a mild serum defect which was less apparent when her own plasma was used with her serum. At this stage it was impossible to exclude chance variation within the normal range.

We were unable to repeat the tests until July, 1958 (Fig. 2). The platelet count was then 2,000,000 per c.mm. and the prothrombin index $100 \%$. The tests were carried out using, respectively, pooled normal platelet suspension, brain extract platelet substitute (Bell and Alton, 1954), and the patient's own platelets, unstandardized and standardized by dilution to conform to a normal peripheral platelet count.

In each test the same phenomena were observed, but the serum defect had become more obvious. This defect was partially corrected by the patient's $\mathrm{Al}(\mathrm{OH})_{3}$-treated plasma, which itself behaved normally when tested with normal serum. In contrast with the more usual findings in Christmas disease, the curves reached normal levels after four to seven minutes' incubation. It is of interest to note (Fig. 2) that this defect is at least as obvious when using platelet substitute as when using suspensions of either normal or patient's platelets.

A further series of tests was performed in November, 1958, on blood collected in October, before treatment with ${ }^{32} \mathrm{P}$. They were carried out using platelet substitute and patient's standardized platelets respectively. The patient's plasma and serum had been stored at $-20^{\circ}$ C. for three weeks.

Similar results were again noted and the correcting ability of the plasma was still present (Fig. 3). Two weeks later, however, using the same plasma and serum, although the serum defect remained, this had now disappeared (Fig. 4a). In order to confirm that this was in fact a Christmas factor deficiency the serum was tested against two known Christmas disease sera, one kindly supplied by Dr. F. G. Bolton (Fig. 4b). No mutual correction could be demonstrated. Owing to the shortage of plasma and the difficulty in contacting the patient, we were most unfortunately unable to test her plasma against known Christmasdeficient serum.

In November, 1958, three and a half weeks after the administration of ${ }^{32} \mathbf{P}$, when the platelet count had fallen to 500,000 per c.mm., blood was again collected and tested (Fig. 5). There was now no abnormality in thromboplastin generation. Since traces of thromboplastin in the plasma could have given an apparent correction of the patient's original serum defect in the thromboplastin generation test the possibility arose that during the preparation of this plasma for the test, excess of platelets might have produced so much that some remained
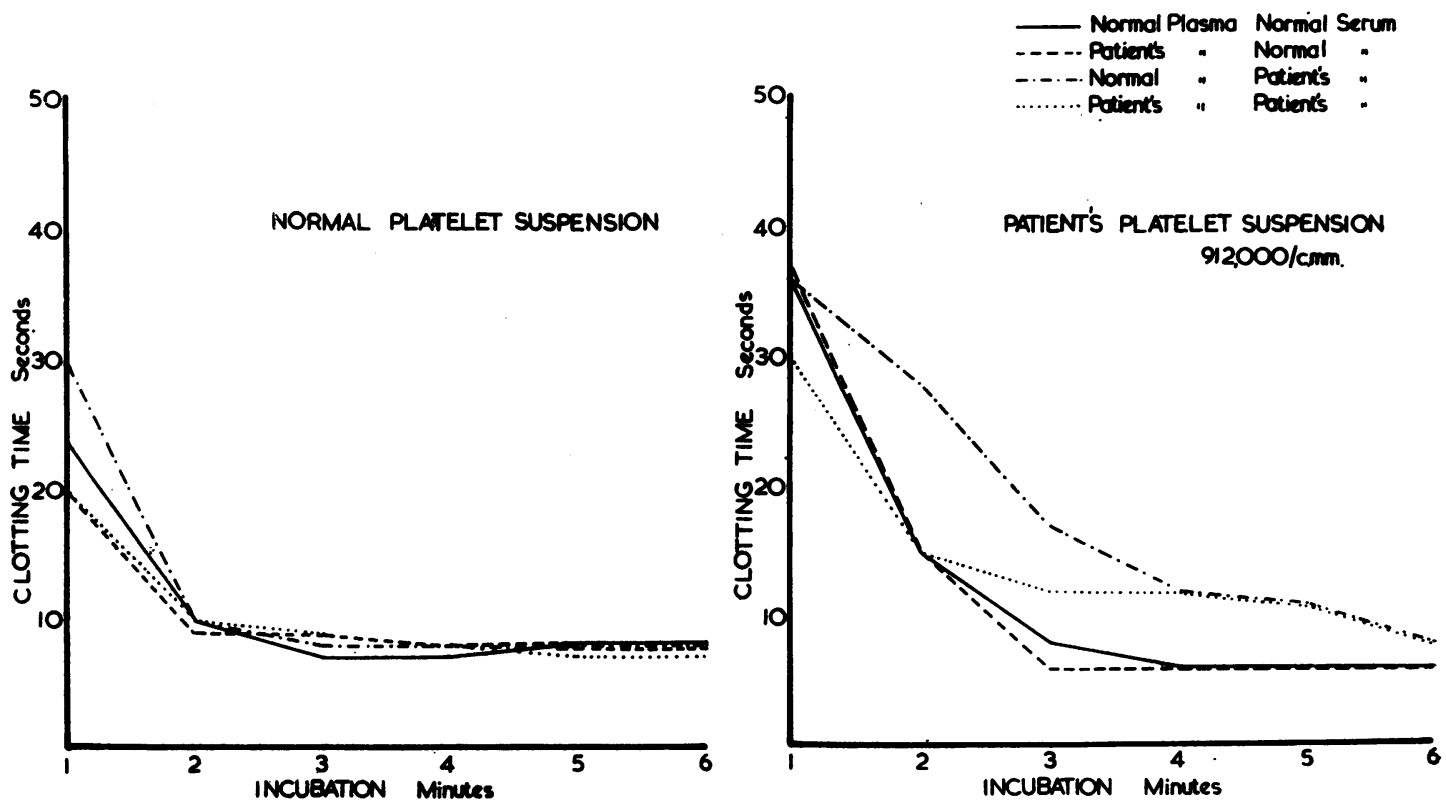

Fig. 1.-Results of tests performed in 1956. 
unabsorbed, in spite of the recognized avidity of the $\mathrm{Al}(\mathrm{OH})_{3}$ for it. The limited experiment described above was devised to exclude this.

Dr. Bolton kindly carried out assays of Christmas factor in these sera. Before treatment the level was $30 \%$; three and a half weeks after treatment it had risen to $55 \%$, and two months later it was $137 \%$. The lower limit of normal for this method is $68 \%$ (Bolton and Clarke, 1959).
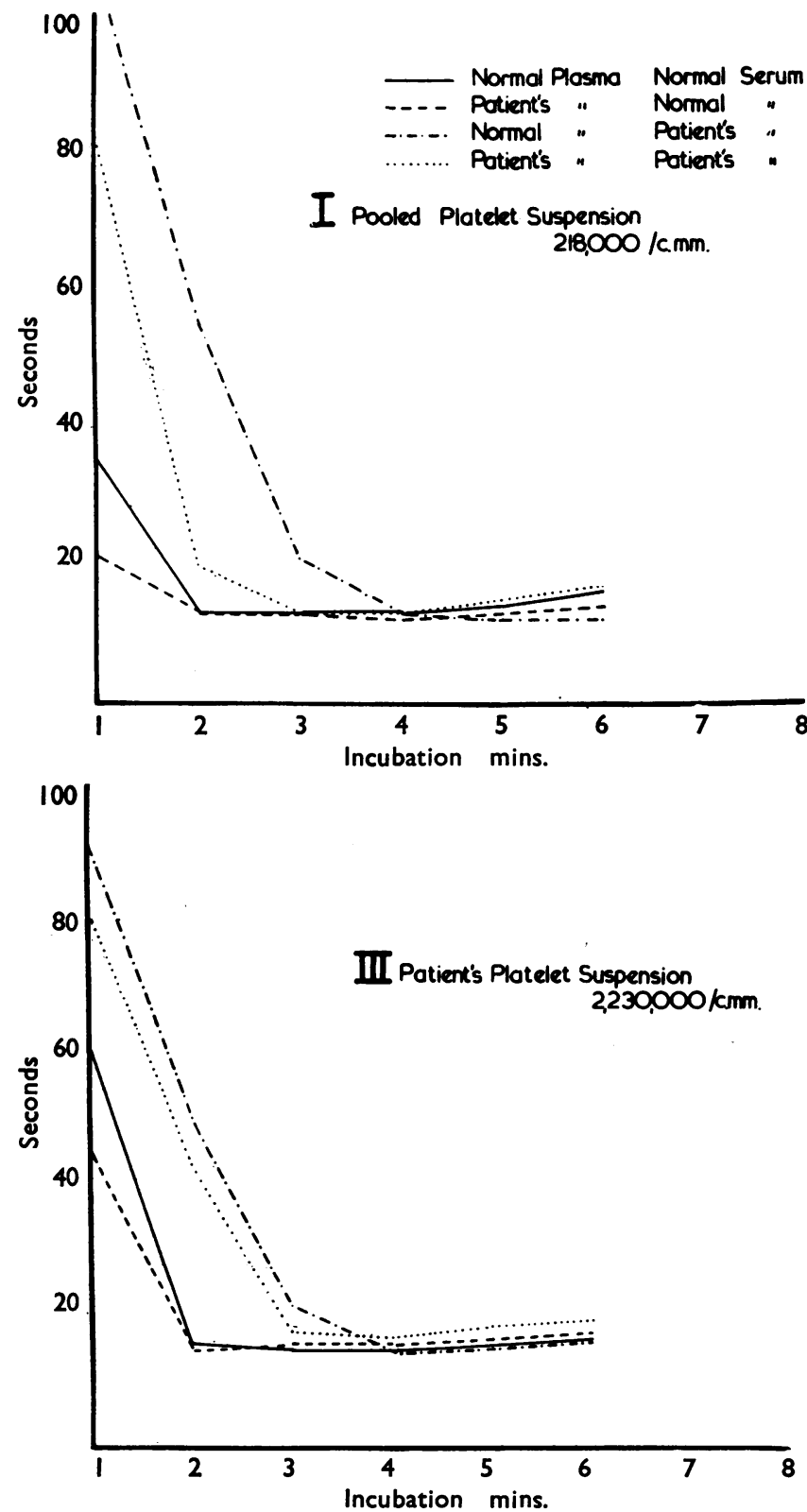

\section{Discussion}

Using the thromboplastin generation test, Hardisty and Wolff (1955) in five, and Shaw and Oliver (1958) in six, cases of thrombocythaemia found evidence of platelet dysfunction. Soulier, Alagille, and Labrieu (1957) were unable to find any consistent abnormality amongst 27 cases, and Fountain (1958) in two found no abnormality at
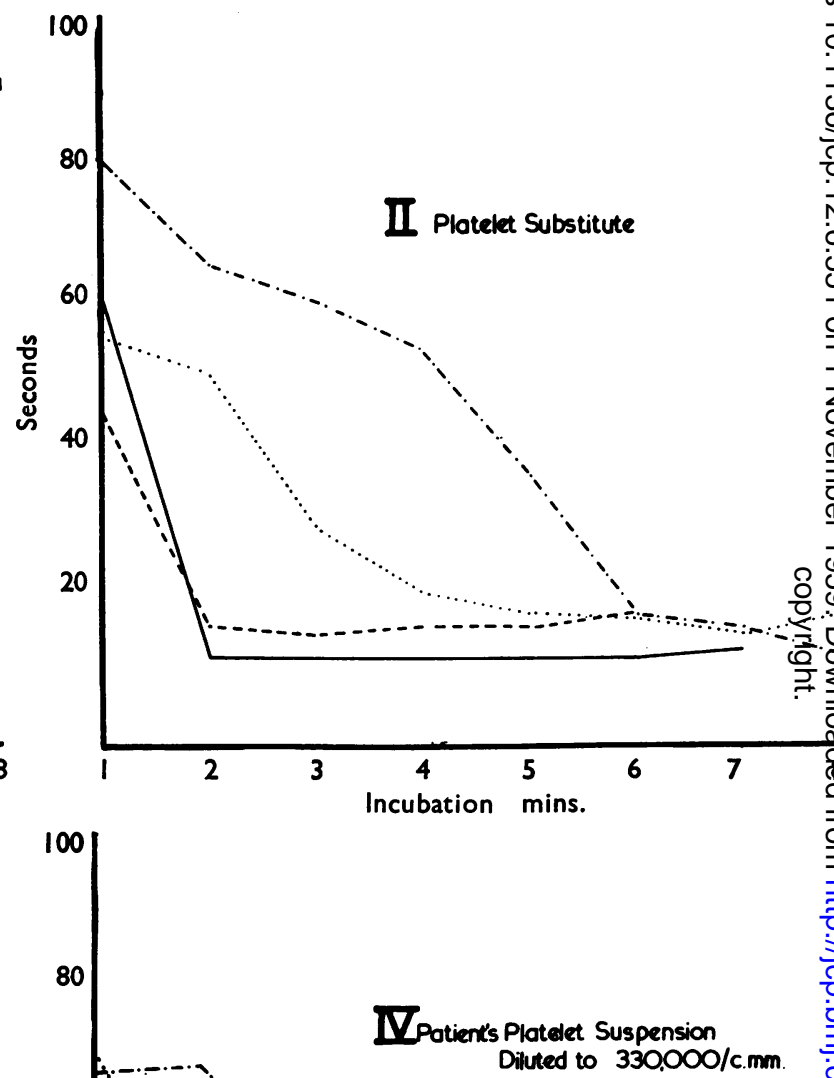

FIG. 2.-Results of tests performed in July, 1958.

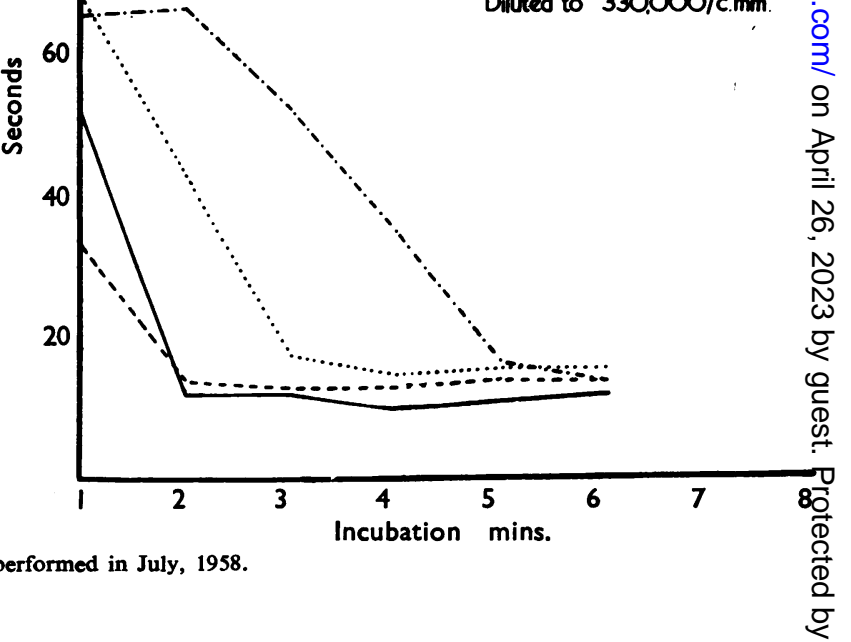



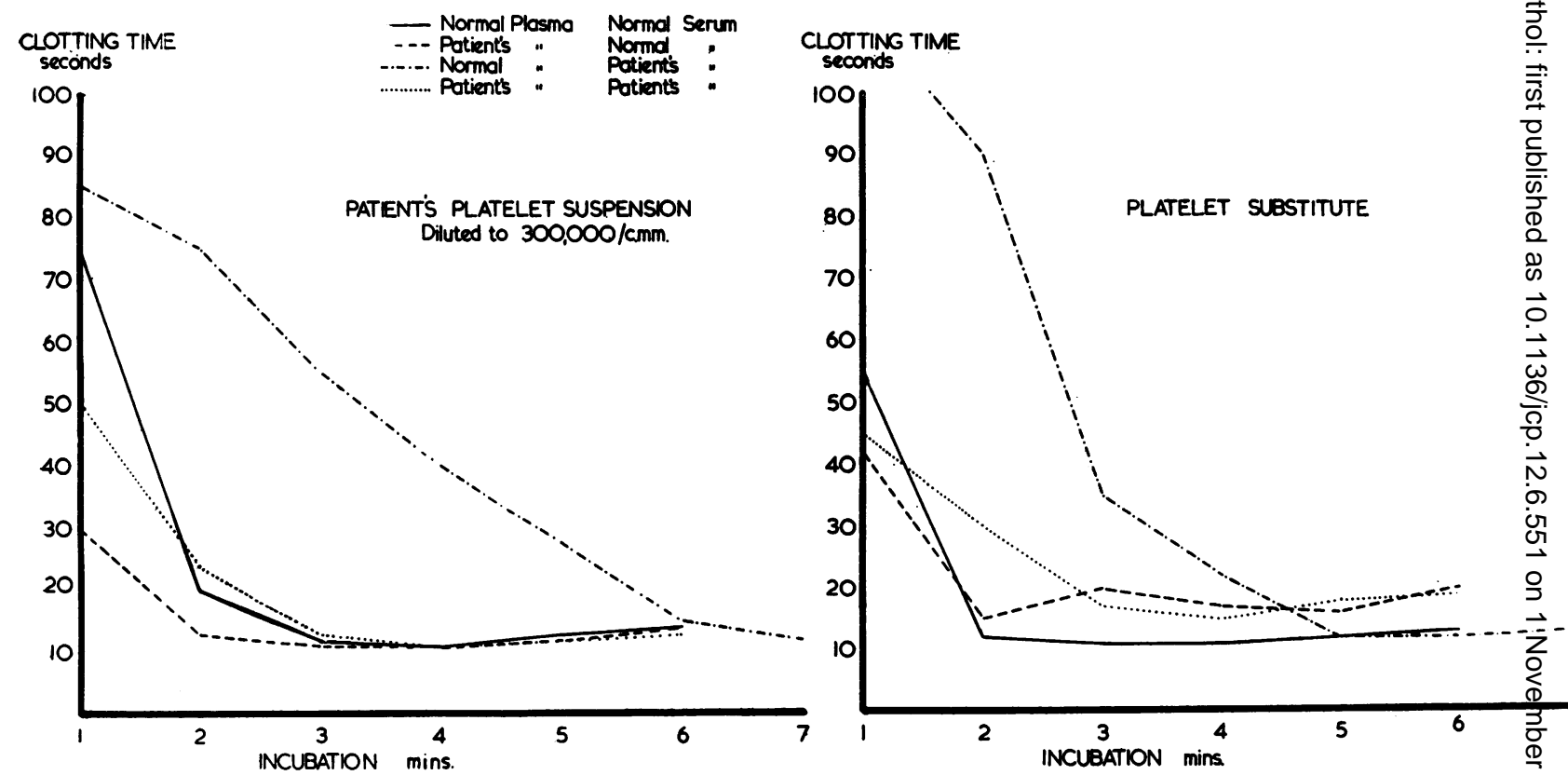

FIG. 3.-Tests performed on blood collected in October, 1958, before treatment with ${ }^{32}$ P. (Plasma and serum had been stored for three weeks before testing.)

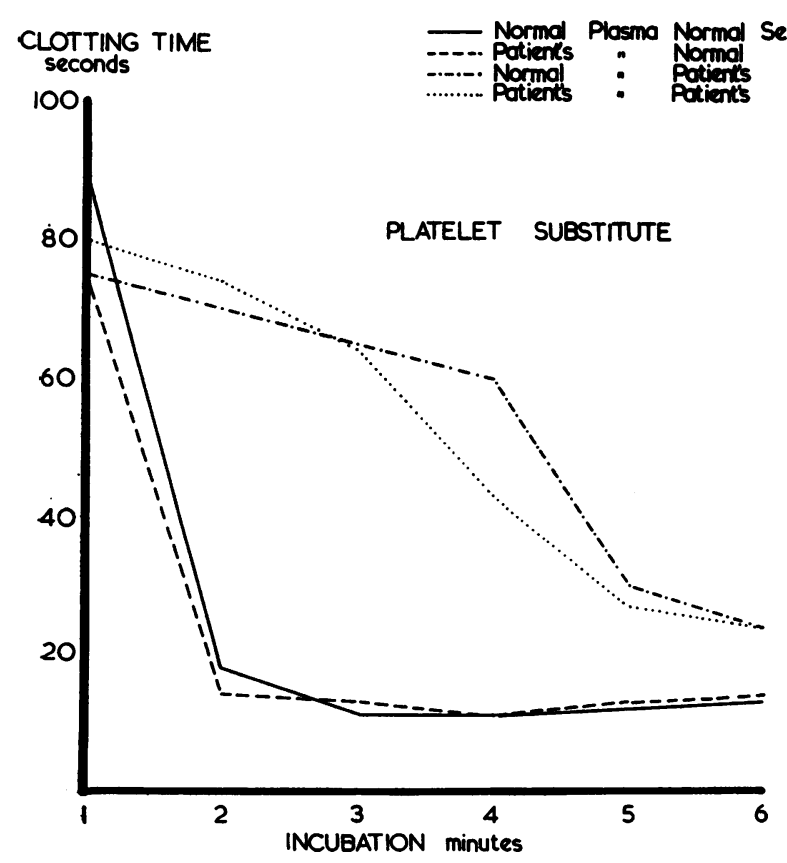

(a)

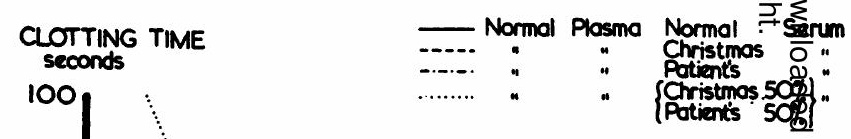

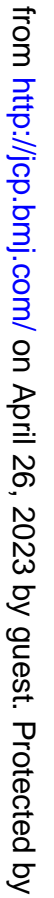




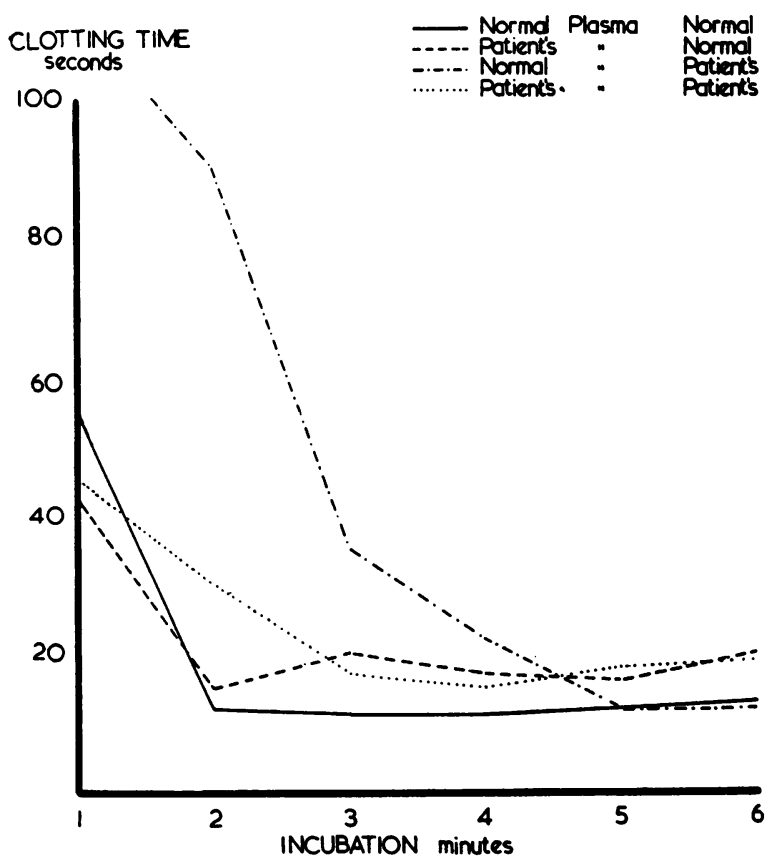

BEFORE TREATMENT

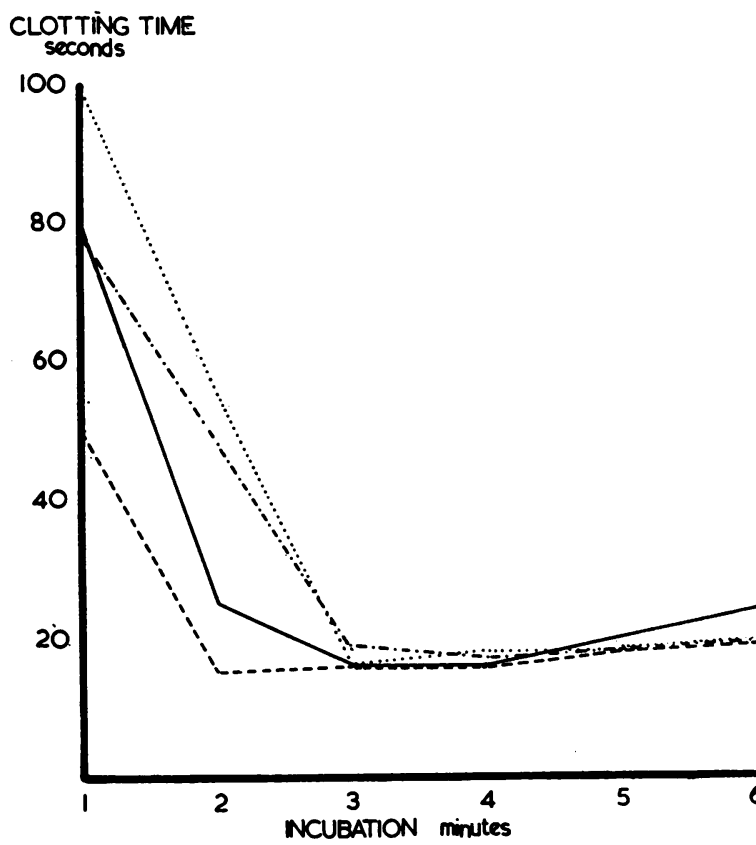

AFTER TREATMENT WITH $32 p$

Fig. 5.-Comparison of results of tests before (October, 1958) and after (November, 1958) treatment.

all. Of these, only Fountain tested the patient's plasma and serum. It is of interest that Bonnin (1956) and Perry and Craddock (1958) were able to restore normal function to defective platelets by incubating them in normal plasma and serum, although their cases were not thrombocythaemic. There is thus a wide range of results, but the emphasis has been on platelet function.

In our case a serum defect has been observed and, although tests have been performed on one occasion only since the platelet count has fallen, the fact that it has now disappeared points to a link between it and the thrombocythaemia. This defect appears to be identical with Christmas disease, in so far as we have been able to establish it against known Christmas disease sera.

The key seems to lie in the ability of this patient's plasma to correct her own serum defect. It is not unreasonable, therefore, to assume that the total Christmas factor in her blood is not appreciably diminished and that, during the process of clotting, some only of it is liberated into the serum. Christmas factor is readily absorbed from plasma by $\mathrm{Al}(\mathrm{OH})_{3}$. Since the patient's plasma after such treatment is able to correct the serum defect, in contradistinction to normal plasma so treated, it could indicate that the Christmas factor in the patient's plasma differs from that in normal plasma, in that it is not so readily absorbed. In view of Bergsagel's work (1955), in which it is suggested that Christmas factor exists normally in an inactive form, becoming activated in the presence of calcium and A.H.G. (VIII) in the initial stages of clotting, this difference may merely mean that the Christmas factor in the patient's plasma has only been partially activated and that the inactivated fraction is resistant to absorption ; it then undergoes complete activation during the thromboplastin generation test, and is thus able to replace the deficiency of Christmas factor in the patient's test serum. The fact that after storage her plasma no longer corrects her serum defect (Fig. 4a) is consistent with a gradual change of this fraction into a form readily absorbed by $\mathrm{Al}(\mathrm{OH})_{3}$. It may also be that only the activated fraction can be liberated into the serum during clotting, which would explain the apparent deficiency in the patient's serum. It would not, however, exclude the possibility that Christmas factor is partially consumed during the process of clotting in the presence of excess platelets (Biggs, 1959, personal communication). 
If this explanation is acceptable, then, in order to explain any association with thrombocythaemia, it becomes possible to postulate that platelets also play a part in the activation of Christmas factor and that any platelet abnormality may interfere with this mechanism. Shaw and Oliver (1958) favour a qualitative abnormality, suggesting that platelets, owing to their rapid formation, may be deficient in some essential factors. Hardisty and Wolff (1955), in fact, demonstrated low platelet serotonin levels in all their five cases. Spaet, Bauer, and Melamed (1956), on the other hand, find it difficult to believe that the excess of platelets in thrombocythaemia is not more than enough to compensate for any mild qualitative defect, and put forward the view that the fundamental defect is a coagulation disorder resulting from the anticoagulant effect of an excess of normal platelets. They quote Tocantins and Carroll (1949) and Klein and Farber (personal communication) in support. Shaw and Oliver also suggest this as an alternative.

In our case, such an explanation does not in itself account for the correcting phenomenon, but it does lend support to one based on a quantitative defect. Our findings may merely mean that a sufficient increase in the number of platelets alone can throw the activating mechanism out of balance, resulting in an apparent but not real deficiency of Christmas factor. On the other hand it is possible that an excess of A.H.G. may also do this and, in the thromboplastin generation test itself, mask rather than correct by replacement a Christmas deficiency in the serum (Biggs, 1959, personal communication). O'Brien (1959) has recently suggested that heparin inhibits the activation of Christmas factor in the earliest stages of clotting. We have been unable to assess either mechanism in our case.

It is difficult to be dogmatic when one considers the variety of apparent defects found in association with thrombocythaemia, and also the complexity of the coagulation mechanism itself. But explanations based on optimum concentrations do allow of a range of reactions when the equilibrium is disturbed. Nevertheless, this Christmas factor defect, if it represents a true Christmas disease found coincidently, is a curious one in that it was most in evidence when the platelets were high, started to disappear as they fell in response to ${ }^{32} \mathrm{P}$, and ceased to be demonstrable when they had reached a normal level. The argument that the defect in our case is intimately associated with the thrombocythaemia, as part of the syndrome of haemorrhagic thrombocythaemia, is difficult to resist.

\section{Summary}

A case of haemorrhagic thrombocythaemia is described having a Christmas factor (Factor IX) serum deficiency which is corrected in the thromboplastin generation test by the patient's $\mathrm{Al}(\mathrm{OH})_{3}$-treated plasma. After treatment with ${ }^{32} \mathrm{P}$ this deficiency as shown in the thromboplastin generation test disappeared, and the Christmas factor assay, previously low, returned to normal.

It is suggested: (a) that in the initial stages of clotting an optimum concentration of platelets may be necessary for the full activation of Christmas factor.

(b) That if this is so, the deficiency of Christmas factor in the serum may be due to retention or consumption of the inactivated fraction during clotting.

We wish to thank Dr. J. M. Naish and Dr. Alistair MacLeod for their kindness in allowing us to investigate and report this case, Mr. G. Crane for his considerable assistance, Dr. F. G. Bolton for kindly assaying the Christmas factor for us, and Dr. Rosemary Biggs for her invaluable criticism in preparing this paper. Last but not least we would like to thank the patient for her invariable patience and her intense interest in everything we were doing.

\section{REFERENCES}

Bell, W. N., and Alton, H. G. (1954). Nature (Lond.), 174, 880 Bergsagel, D. E. (1955). Brit. J. Haemat., 1 , 199.

Biggs, R., and Douglas, A. S. (1953). J. clin. Path., 6, 23.

- and MacFarlane, R. G. (1957). Human Blood Coagulation and Its Disorders, 2nd ed. Blackwell, Oxford.

Bolton, F. G., and Clarke, J. E. (1959). In press.

Bonnin, J. A.'(1956). Brit. J. Haemat., 2, 160

Dacie, J. V. (1950). Practical Haematology. Churchill, London.

Fanger, H., Cella, L. J., and Litchman, H. (1954). New Engl. J. Med., $250,456$.

Fountain, J. R. (1958). Brit. med. J., 2, 126.

Hardisty, R. M., and Wolf, H. H. (1955). Brit. J. Haemat., 1, 390.

O'Brien, J. R. (1959). J. clin. Path., 12, 386.

Perry, S., and Craddock, C. G. (1958). Blood, 13, 177

Shaw, S., and Oliver, R.A. M. (1958). Proc. roy. Soc. Med., 51, 768.

Soulier, J. P., Alagille, D., and Labrieu, M. J. (1957). Sang, 28, 277.

Spaet, T. H., Bauer, S., and Melamed, S. (1956). Arch. intern. Med., 98, 377.' 